\title{
Colloidal Synthesis and Optical Properties of Perovskite-Inspired Cesium Zirconium Halide Nanocrystals
}

Anna Abfalterer, Javad Shamsi, Dominik J. Kubicki, Christopher N. Savory, James Xiao, Giorgio Divitini, Weiwei Li, Stuart Macpherson, Krzysztof Gałkowski, Judith L. MacManus-Driscoll, David O. Scanlon, and Samuel D. Stranks*

ABSTRACT: Optoelectronic devices based on lead halide perovskites are processed in facile ways, yet are remarkably efficient. There are extensive research efforts investigating leadfree perovskite and perovskite-related compounds, yet there are challenges to synthesize these materials in forms that can be directly integrated into thin film devices rather than as bulk powders. Here, we report on the colloidal synthesis and characterization of lead-free, antifluorite $\mathrm{Cs}_{2} \mathrm{ZrX}_{6}(\mathrm{X}=\mathrm{Cl}, \mathrm{Br})$ nanocrystals that are readily processed into thin films. We use transmission electron microscopy and powder X-ray diffraction measurements to determine their size and structural properties, and solid-state nuclear magnetic resonance measurements reveal the presence of oleate ligand, together with a disordered

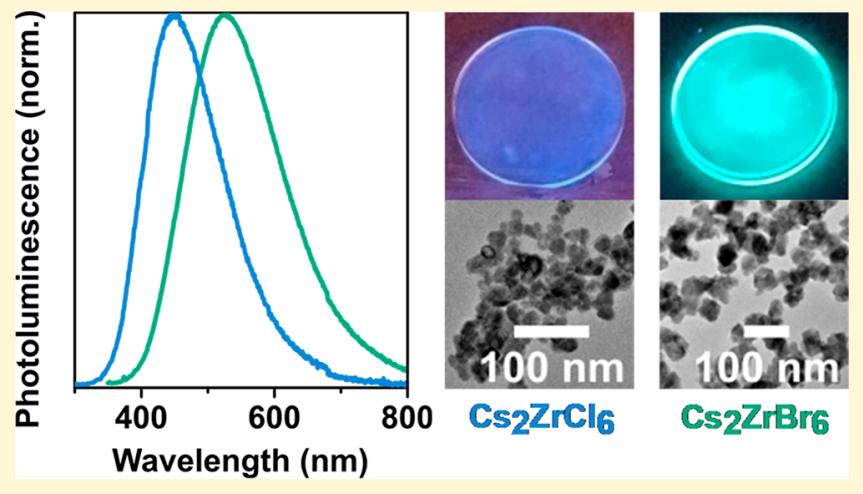
distribution of Cs surface sites. Density functional theory calculations reveal the band structure and fundamental band gaps of 5.06 and $3.91 \mathrm{eV}$ for $\mathrm{Cs}_{2} \mathrm{ZrCl}_{6}$ and $\mathrm{Cs}_{2} \mathrm{ZrBr}_{6}$, respectively, consistent with experimental values. Finally, we demonstrate that the $\mathrm{Cs}_{2} \mathrm{ZrCl}_{6}$ and $\mathrm{Cs}_{2} \mathrm{ZrBr}_{6}$ nanocrystal thin films exhibit tunable, broad white photoluminescence with quantum yields of $45 \%$ for the latter, with respective peaks in the blue and green spectral regions and mixed systems exhibiting properties between them. Our work represents a critical step toward the application of lead-free $\mathrm{Cs}_{2} \mathrm{ZrX}_{6}$ nanocrystal thin films into nextgeneration light-emitting applications.

$\mathrm{M}$ etal halide perovskite materials with the general formula $\mathrm{ABX}_{3}$ (where $\mathrm{A}=$ cation, $\mathrm{B}=$ metal cation (typically $\mathrm{Pb}^{2+}$ ), and $\mathrm{X}=$ halide anion) have shown excellent performance in optoelectronic devices. ${ }^{1}$ Their facile fabrication renders them attractive for scaled-up production; however, limited operational lifetimes of perovskite-based devices, as well as the toxicity of lead, remain major issues, ${ }^{2,3}$ particularly for consumer electronics applications. Consequently, there is motivation to find viable lead replacements for these materials. The two mainstream approaches for lead replacement rely on incorporation of either homovalent ions (such as $\mathrm{Ge}^{2+}$ or $\mathrm{Sn}^{2+}$ ) or heterovalent ions (such as $\mathrm{Sb}^{3+}$ or $\left.\mathrm{Bi}^{3+}\right){ }^{4}$ The latter approaches require ion-splitting or the occurrence of ordered vacancies to maintain charge neutrality, thereby creating halide perovskites or perovskite derivatives with altered chemical formulas, such as $\mathrm{AB}(\mathrm{Ch}, \mathrm{X})_{3}$, $\mathrm{A}_{2} \mathrm{~B}^{1+} \mathrm{B}^{3+} \mathrm{X}_{6}, \mathrm{~A}_{3} \square \mathrm{B}^{3+}{ }_{2} \mathrm{X}_{9}$, and $\mathrm{A}_{2} \square \mathrm{B}^{4+} \mathrm{X}_{6}$ (with $\mathrm{Ch}$ denoting a chalcogen and the open box symbol $(\square)$ indicating a vacancy). ${ }^{4}$
Many of these $\mathrm{A}_{2} \mathrm{BX}_{6}$ materials, often loosely referenced as vacancy-ordered double perovskites, ${ }^{5}$ adopt the $\mathrm{K}_{2} \mathrm{PtCl}_{6}$ (antifluorite) crystal structure, where isolated $\left[\mathrm{BX}_{6}\right]^{2-}$ octahedra form a face-centered cubic lattice with the A-site cations occupying all tetrahedral sites. The isolated nature of the octahedra and subsequent opportunity for localizing excitations renders these $\mathrm{A}_{2} \mathrm{BX}_{6}$ materials particularly promising for light-emitting applications. The latest works on leadfree perovskite alternatives, particularly $\mathrm{A}_{2} \mathrm{BX}_{6}$ materials, often report the synthesis and characterization of single crystals or bulk powders, ${ }^{6,7}$ which are not compatible with facile thin film

Received: August 20, 2020

Accepted: October 27, 2020

Published: November 11, 2020 

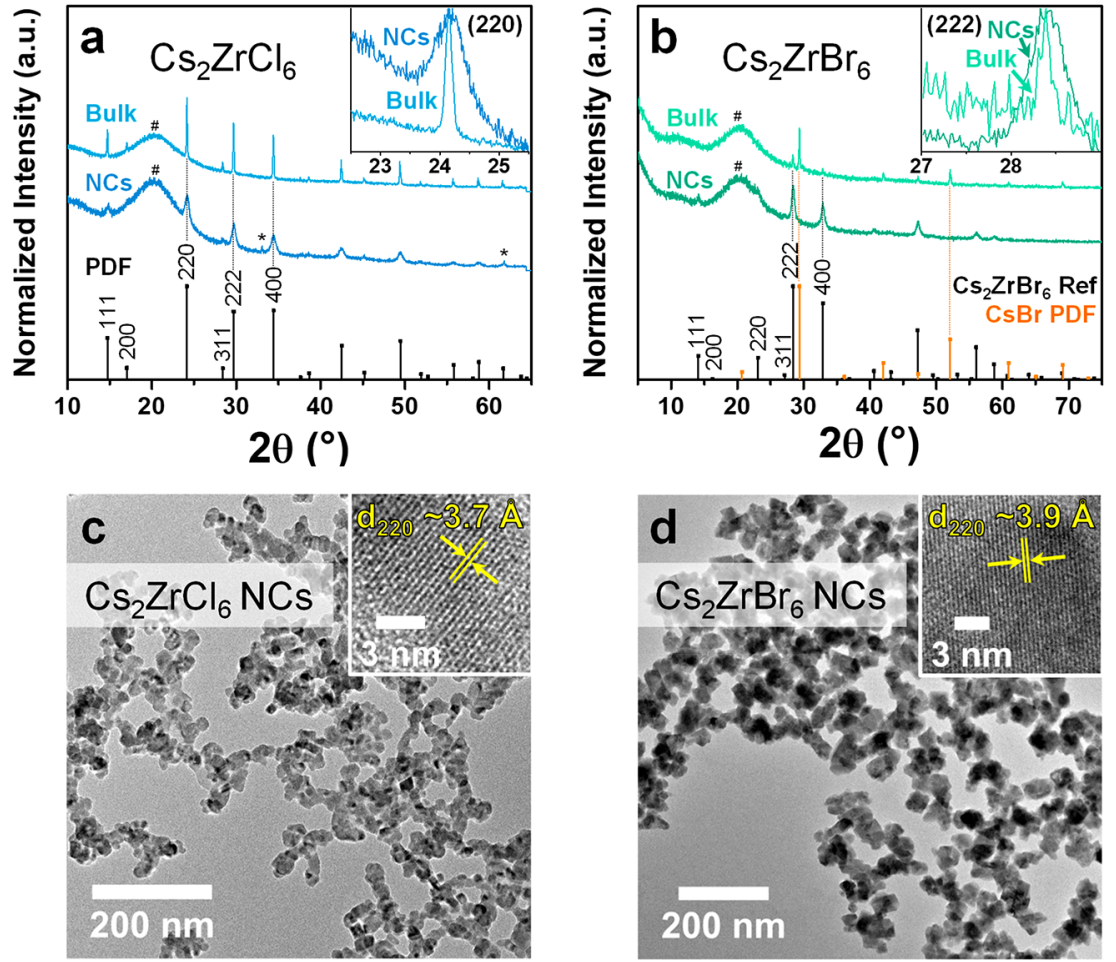

Figure 1. XRD and TEM characterization of solid-state $\mathrm{Cs}_{2} \mathrm{ZrX}_{6}$ samples. (a) $\mathrm{XRD}$ patterns of $\mathrm{Cs}_{2} \mathrm{ZrCl}_{6}$ bulk powder (light blue) and a $\mathrm{Cs}_{2} \mathrm{ZrCl}_{6} \mathrm{NC}$ thin film (blue), as well as the reference XRD pattern of $\mathrm{Cs}_{2} \mathrm{ZrCl}_{6}$ (JCPDS File No. 01-074-1001, shown in black). ${ }^{20}$ The diffraction patterns are normalized to the respective maximum intensity of the scans and are vertically offset for clarity. The air-free sample holder introduces a broad background and a peak at $\sim 20^{\circ}$ (marked with a hash symbol (\#)); the asterisks $(*)$ mark peaks that originate from the Si substrate. The inset shows an expanded comparison of the (220) XRD peaks of $\mathrm{Cs}_{2} \mathrm{ZrCl}_{6}$ bulk powder with the $\mathrm{Cs}_{2} \mathrm{ZrCl}_{6} \mathrm{NC}$ thin film. The patterns are normalized to the maximum peak intensity and scaled between 0 and 1 along the ordinate, respectively. (b) XRD patterns of $\mathrm{Cs}_{2} \mathrm{ZrBr}_{6}$ bulk powder (light green; including $\mathrm{CsBr}$ phase impurity) and a $\mathrm{Cs}_{2} \mathrm{ZrBr}_{6} \mathrm{NC}$ thin film (green) as well as the reference $\mathrm{XRD}$ pattern of $\mathrm{Cs}_{2} \mathrm{ZrBr}_{6}$ (shown in black; see the SI for details on calculation) and CsBr (JCPDS File No. 00-005-0588, shown in orange). ${ }^{22}$ The diffraction patterns are normalized to the respective maximum intensity of the scans and vertically offset for clarity. The air-free sample holder introduces a broad background and peak at $\sim 20^{\circ}$ (marked with a hash symbol (\#)). The inset shows an expanded view comparing the (222) XRD peaks of $\mathrm{Cs}_{2} \mathrm{ZrBr}_{6}$ bulk powder with the $\mathrm{Cs}_{2} \mathrm{ZrBr}_{6} \mathrm{NC}$ thin film. The patterns are normalized to the maximum peak intensity and scaled between 0 and 1 along the ordinate, respectively. For both $\mathrm{Cs}_{2} \mathrm{ZrCl}_{6}$ and $\mathrm{Cs}_{2} \mathrm{ZrBr}_{6}$ reference XRD patterns, we index the first six diffraction peaks to the respective $(h \mathrm{kl})$ planes, according to the powder diffraction file $(\mathrm{PDF})$ for $\mathrm{Cs}_{2} \mathrm{ZrCl}_{6}$ and the simulated reference $\mathrm{XRD}$ pattern for $\mathrm{Cs}_{2} \mathrm{ZrBr}_{6}$. (c) TEM image of $\mathrm{Cs}_{2} \mathrm{ZrCl}_{6}$ NCs. The inset shows a HR-TEM image (see Figure S2 in the SI for a larger area) of a $\mathrm{Cs}_{2} \mathrm{ZrCl}_{6} \mathrm{NC}$, showing (220) lattice fringes separated by $\sim 3.7 \AA$. (d) TEM image of $\mathrm{Cs}_{2} \mathrm{ZrBr}_{6}$ NCs. The inset shows an HR-TEM image (see Figure S3 in the Supporting Information for a larger area) of a $\mathrm{Cs}_{2} \mathrm{ZrBr}_{6} \mathrm{NC}$, showing (220) lattice fringes separated by $\sim 3.9 \AA$.

integration required for device applications. So far, thin films of $\mathrm{A}_{2} \mathrm{BX}_{6}$ materials, for example, have been fabricated for $\mathrm{Cs}_{2} \mathrm{PdBr}_{6}{ }^{8} \mathrm{Cs}_{2} \mathrm{TiBr}_{6},{ }^{9}$ and $\mathrm{Cs}_{2} \mathrm{SnI}_{6},{ }^{10}$ but this is only a small subset of all experimentally known $\mathrm{A}_{2} \mathrm{BX}_{6}$ materials; this small sample space limits us from exploiting the full family of these materials for optoelectronic device application. One approach to fabricate thin films with excellent optoelectronic properties is through deposition of colloidal suspensions of nanocrystals (NCs), yet only $\mathrm{Sn}^{4+}$ - or $\mathrm{Pd}^{4+}$-based $\mathrm{A}_{2} \mathrm{BX}_{6} \mathrm{NC}$ systems ${ }^{11,12}$ have been reported to date.

Here, we report the novel synthesis and characterization of colloidal, antifluorite cesium hexachlorozirconate(IV) and cesium hexabromozirconate(IV) NCs, thereby opening up the range of tunable antifluorite NC compositions. Powder Xray diffraction (XRD) measurements show that the $\mathrm{Cs}_{2} \mathrm{ZrX}_{6}$ $(\mathrm{X}=\mathrm{Cl}, \mathrm{Br}) \mathrm{NCs}$ crystallize into the antifluorite structure. Solid-state nuclear magnetic resonance (NMR) experiments validate that the surfaces of $\mathrm{Cs}_{2} \mathrm{ZrCl}_{6} \mathrm{NCs}$ are capped with oleate ligands and a disordered distribution of Cs sites. Using density functional theory (DFT), we calculate fundamental band gaps of $5.06 \mathrm{eV}$ for $\mathrm{Cs}_{2} \mathrm{ZrCl}_{6}$ and $3.91 \mathrm{eV}$ for $\mathrm{Cs}_{2} \mathrm{ZrBr}_{6}$, which is consistent with the experimentally measured values and band structure. Thin films of $\mathrm{Cs}_{2} \mathrm{ZrCl}_{6}$ and $\mathrm{Cs}_{2} \mathrm{ZrBr}_{6} \mathrm{NCs}$ show broad photoluminescence (PL) peaking at $\sim 450 \mathrm{~nm}$ (blue-white) and $\sim 528 \mathrm{~nm}$ (green-white), respectively, with the bromide system exhibiting a photoluminescence quantum yield (PLQY) of $45 \%$. By mixing the colloidal suspensions of $\mathrm{Cs}_{2} \mathrm{ZrCl}_{6}$ and $\mathrm{Cs}_{2} \mathrm{ZrBr}_{6} \mathrm{NCs}$ and depositing films, we demonstrate tunable white emission, which is not limited by anion exchange reactions, as is otherwise the case for leadbased $\mathrm{CsPbX}_{3} \mathrm{NC}$ systems. ${ }^{13,14}$ These results reveal that halide engineering is a viable strategy for tuning the optical properties of $\mathrm{Cs}_{2} \mathrm{ZrX}_{6} \mathrm{NC}$ thin films, and that they will be particularly interesting for light-emission applications requiring optically homogeneous thin films such as light-emitting diodes and scintillators. $^{15,16}$

Using strict air-free Schlenk line techniques, in conjunction with a hot-injection approach, we fabricate colloidal suspensions of $\mathrm{Cs}_{2} \mathrm{ZrCl}_{6}$ NCs. Specifically, we rapidly inject benzoyl chloride diluted in dried 1-octadecene (ODE) into a solution of stoichiometric quantities of cesium and zirconium precursors in a mixture of oleylamine (OLA) and oleic acid 

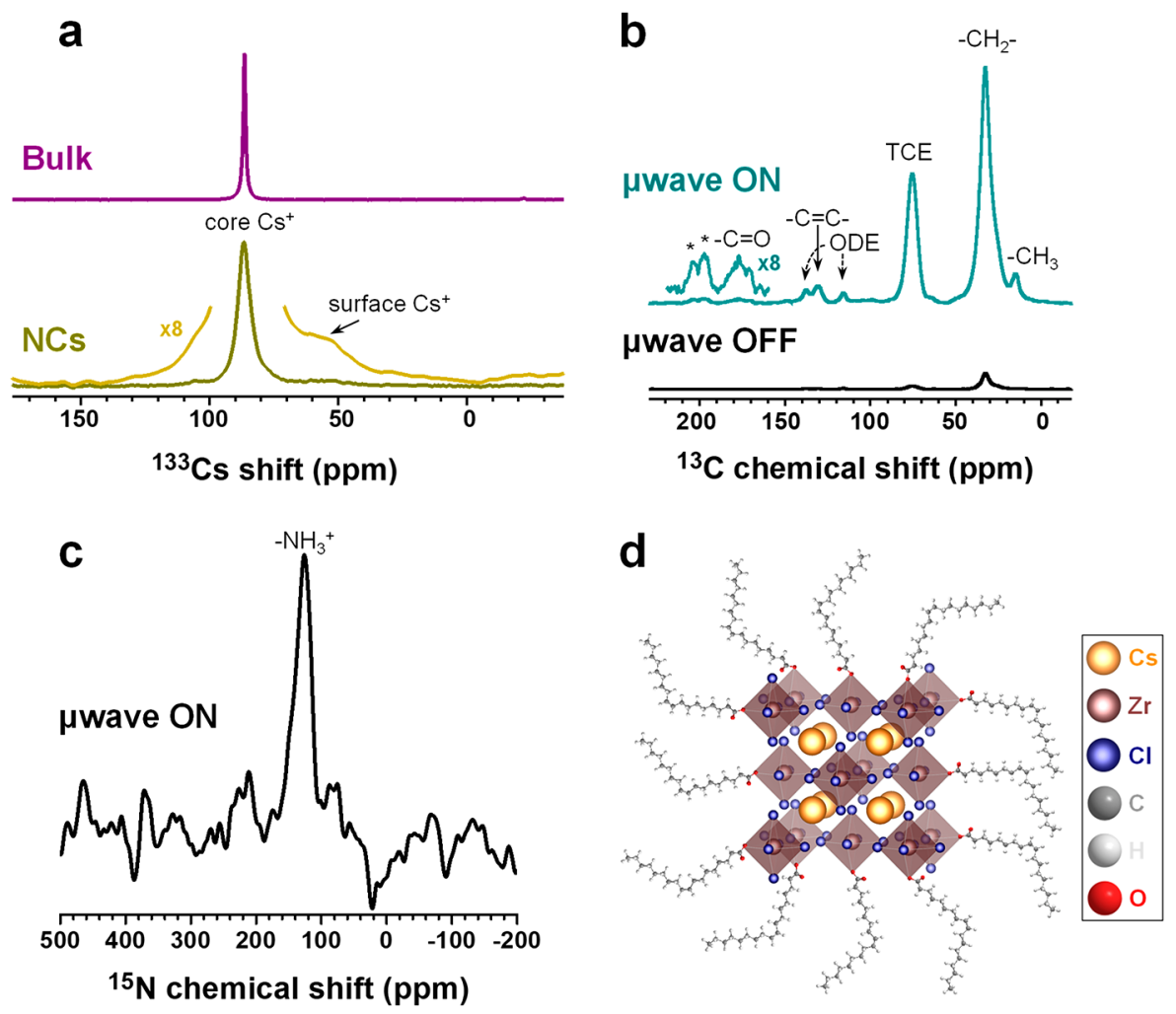

Figure 2. Solid-state MAS NMR characterization of $\mathrm{Cs}_{2} \mathrm{ZrCl}_{6}$ samples. (a) ${ }^{133} \mathrm{Cs}$ echo-detected spectrum of $\mathrm{Cs}_{2} \mathrm{ZrCl}_{6}$ bulk powders (at 10 $\mathrm{kHz}$ MAS) and a Bloch decay (single pulse) spectrum of $\mathrm{Cs}_{2} \mathrm{ZrCl}_{6} \mathrm{NCs}$ (at $12 \mathrm{kHz}$ MAS) at $16.4 \mathrm{~T}$ and RT. The spectra are vertically offset for clarity. The arrow indicates a broad signal corresponding to surface $\mathrm{Cs}^{+}$sites of the $\mathrm{Cs}_{2} \mathrm{ZrCl}_{6} \mathrm{NCs}$. $(\mathrm{b}){ }^{1} \mathrm{H}-{ }^{13} \mathrm{C} \mathrm{CP}$ spectrum of the carbon-containing species in a $\mathrm{Cs}_{2} \mathrm{ZrCl}_{6} \mathrm{NC}$ sample recorded under DNP SENS conditions. The asterisks $(*)$ indicate spinning sidebands. (c) ${ }^{1} \mathrm{H}-{ }^{15} \mathrm{~N}$ CP spectrum recorded under DNP SENS conditions evidencing the presence of highly disordered $-\mathrm{NH}_{3}{ }^{+}$environments in a $\mathrm{Cs}_{2} \mathrm{ZrCl}_{6} \mathrm{NC}$ sample. (d) Schematic of an oleate-capped $\mathrm{Cs}_{2} \mathrm{ZrCl}_{6} \mathrm{NC}$.

(OA) in $\mathrm{ODE}$ at $185^{\circ} \mathrm{C}$, then isolate and redisperse the $\mathrm{NCs}$ in toluene, following previous reports on the synthesis of halide perovskite $\mathrm{NCs}^{17,18}$ (see Supporting Information (SI) for details). We also fabricated $\mathrm{Cs}_{2} \mathrm{ZrBr}_{6}$ NCs using a similar method but without addition of OLA; we found that omission of OLA also leads to more reliable and reproducible syntheses of the $\mathrm{Cs}_{2} \mathrm{ZrCl}_{6} \mathrm{NCs}$ (see the SI and NMR section below). The synthesis of bulk $\mathrm{Cs}_{2} \mathrm{ZrCl}_{6}$ and $\mathrm{Cs}_{2} \mathrm{ZrBr}_{6}$ reference powders follows a published method with slight modifications $^{19}$ (see the SI for details).

Figures $1 \mathrm{a}$ and $1 \mathrm{~b}$ show the XRD patterns of bulk powder and $\mathrm{NC}$ samples of $\mathrm{Cs}_{2} \mathrm{ZrCl}_{6}$ and $\mathrm{Cs}_{2} \mathrm{ZrBr}_{6}$, respectively, measured under air-free conditions using an air-free sample holder. Here, we prepared the NC thin film samples by depositing the colloidal suspensions of $\mathrm{Cs}_{2} \mathrm{ZrCl}_{6} \mathrm{NCs}$ on a $\mathrm{Si}$ substrate and of $\mathrm{Cs}_{2} \mathrm{ZrBr}_{6} \mathrm{NCs}$ on a glass substrate. The patterns in Figure 1a match the reference XRD pattern of $\mathrm{Cs}_{2} \mathrm{ZrCl}_{6}$ (Joint Committee on Powder Diffraction Standards (JCPDS) File No. 01-074-1001, space group $F m \overline{3} m, a=$ $10.407 \AA$ ),${ }^{20}$ suggesting that the samples are phase-pure with any phase impurities at concentrations below the detection limit or amorphous in nature. The corresponding pure $\mathrm{Cs}_{2} \mathrm{ZrBr}_{6}$ reference XRD pattern is not available from the literature; therefore, we calculated a crystallographic information file (CIF) for $\mathrm{Cs}_{2} \mathrm{ZrBr}_{6}$, by replacing $\mathrm{Cl}$ with $\mathrm{Br}$ in the structure of $\mathrm{Cs}_{2} \mathrm{ZrCl}_{6}$ and performed a full hybrid DFT geometry optimization, allowing all lattice parameters to change (see the SI for details and CIF file). We then used the program VESTA ${ }^{21}$ to simulate the reference XRD pattern for $\mathrm{Cs}_{2} \mathrm{ZrBr}_{6}$, as shown in Figure $1 \mathrm{~b}$, with the computed unitcell parameter reduced from $11.16 \AA$ to $10.89 \AA$, to better match the experimental XRD data. From these XRD measurements (Figure 1b), we find that the $\mathrm{NC}$ thin film sample is also phase-pure $\mathrm{Cs}_{2} \mathrm{ZrBr}_{6}$, although the bulk powder contains $\mathrm{CsBr}$ impurities (see $\mathrm{CsBr}$ reference JCPDS File No. 00-005-0588, shown in orange in figure). ${ }^{22}$ We note that extended exposure of the $\mathrm{Cl}$ - and $\mathrm{Br}$-containing compositions to ambient air conditions can lead to the formation of various impurity phases including (but not limited to) $\mathrm{CsCl}$ and $\mathrm{CsBr}$, respectively, in both $\mathrm{NC}$ thin film and bulk powder form (see Figure S1 in the SI for examples), which we attribute to the hygroscopic nature of these compounds. ${ }^{23-25}$ The insets of Figure $1 \mathrm{a}$ and $1 \mathrm{~b}$ compare XRD peaks of the $\mathrm{Cs}_{2} \mathrm{ZrCl}_{6}(220)$ and $\mathrm{Cs}_{2} \mathrm{ZrBr}_{6}(222)$ bulk powder and $\mathrm{NC}$ thin film, respectively. The peak widths are narrower for the bulk powder, which implies larger crystallite sizes, compared to those in the NC thin film samples.

Figures $1 \mathrm{c}$ and $1 \mathrm{~d}$ show transmission electron microscopy (TEM) images for $\mathrm{Cs}_{2} \mathrm{ZrCl}_{6}$ and $\mathrm{Cs}_{2} \mathrm{ZrBr}_{6} \mathrm{NCs}$, respectively. In the high-resolution TEM (HR-TEM) image of a $\mathrm{Cs}_{2} \mathrm{ZrCl}_{6}$ NC (inset of Figure 1c), we observe lattice fringes with $\sim 3.7 \AA$ separation, which we index as the (220) plane of $\mathrm{Cs}_{2} \mathrm{ZrCl}_{6}$. We corroborate this assignment by performing a fast Fourier transform (FFT) analysis of the HR-TEM image (see Figure S2), which confirms the structure of $\mathrm{Cs}_{2} \mathrm{ZrCl}_{6}$ and reveals that the analyzed $\mathrm{Cs}_{2} \mathrm{ZrCl}_{6} \mathrm{NC}$ is oriented along the $[\overline{1} 1 \overline{4}]$ zone axis in the real-space image. In the HR-TEM image of a $\mathrm{Cs}_{2} \mathrm{ZrBr}_{6} \mathrm{NC}$ (inset of Figure 1d), we observe lattice fringes 
with $\sim 3.9 \AA$ separation that index as the (220) plane of $\mathrm{Cs}_{2} \mathrm{ZrBr}_{6}$. FFT analysis of the HR-TEM image (see Figure S3) confirms the structure of $\mathrm{Cs}_{2} \mathrm{ZrBr}_{6}$ and shows that the analyzed $\mathrm{Cs}_{2} \mathrm{ZrBr}_{6} \mathrm{NC}$ is oriented along the $[\overline{1} 11]$ zone axis. We note that the NCs of both halide compositions appear slightly aggregated and, therefore, do not exhibit well-defined shapes, even when washed multiple times (see Figure S4 in the SI), although we attribute this in part to the drop-casting deposition method employed that leads to heterogeneous drying of the solvent on the TEM grid; the NCs are colloidally stable in suspension with slow precipitation occurring over a period of weeks to months that can be easily redispersed by agitating the suspension. Further work would be required to achieve well-dispersed particles upon deposition.

To study the atomic-level microstructure of $\mathrm{Cs}_{2} \mathrm{ZrCl}_{6}$ bulk powders and dried $\mathrm{Cs}_{2} \mathrm{ZrCl}_{6} \mathrm{NCs}$, as well as the surface ligands of the dried NCs, we use solid-state magic angle spinning (MAS) NMR spectroscopy and surface-enhanced dynamic nuclear polarization (DNP SENS) solid-state MAS NMR. DNP SENS has emerged as a powerful extension of solid-state NMR for studying dilute surface species and nanoparticles by providing signal enhancements that, compared to conventional NMR, can reach a factor of 660 for protons. ${ }^{26-30}$ Figure $2 \mathrm{a}$ shows the ${ }^{133} \mathrm{Cs}$ MAS NMR spectrum of $\mathrm{Cs}_{2} \mathrm{ZrCl}_{6}$ bulk powder and dried $\mathrm{Cs}_{2} \mathrm{ZrCl}_{6} \mathrm{NCs}$ (see the SI for details). The spectrum of $\mathrm{Cs}_{2} \mathrm{ZrCl}_{6}$ bulk powder has a single peak (shift $\delta=$ $86 \mathrm{ppm}$, full width at half maximum $(\mathrm{FWHM})=106 \pm 1 \mathrm{~Hz})$, consistent with the presence of a single Cs site in the crystal structure of $\mathrm{Cs}_{2} \mathrm{ZrCl}_{6}$. The spectrum of dried $\mathrm{Cs}_{2} \mathrm{ZrCl}_{6} \mathrm{NCs}$ yields a signal at the same ${ }^{133} \mathrm{Cs}$ shift $(\delta=86 \mathrm{ppm})$ but is considerably broader $(\mathrm{FWHM}=474 \pm 3 \mathrm{~Hz})$, because of the presence of a wider distribution of local cesium environments in the NCs than in the bulk powder sample. In addition, we observe a very broad signal spanning $\sim 80 \mathrm{ppm}$ visible on the vertical zoom $(\times 8)$ of the NC signal, which we attribute to the presence of a particularly large distribution of environments for the surface layer of $\mathrm{Cs}^{+}$ions, because of the intrinsically disordered nature of surfaces, ${ }^{29}$ which are dominant in NC samples (because of the large surface-area-to-volume ratios).

For DNP SENS NMR experiments (see the SI for details), we mix the colloidal suspension of $\mathrm{Cs}_{2} \mathrm{ZrCl}_{6} \mathrm{NCs}$ with hexagonal boron nitride (h-BN), dry the mixture at $\sim 50{ }^{\circ} \mathrm{C}$ in the glovebox, dope it with a stable binitroxide radical (here, TEKPol $)^{31}$ in an inert solvent (1,1,2,2-tetrachloroethane, TCE) and irradiate with continuous wave high power and high-frequency microwaves, which drive the polarization transfer from the radicals to the solvent protons. ${ }^{32}$ This subsequently transfers the increased Boltzmann polarization of the solvent protons to the protons in the surface ligands of the $\mathrm{Cs}_{2} \mathrm{ZrCl}_{6} \mathrm{NCs}$ through spin diffusion and can transfer to ${ }^{133} \mathrm{Cs}$ of $\mathrm{Cs}_{2} \mathrm{ZrCl}_{6}$ through ${ }^{1} \mathrm{H}-{ }^{133} \mathrm{Cs}$ cross-polarization (CP). ${ }^{33,34}$ The purpose of mixing the $\mathrm{Cs}_{2} \mathrm{ZrCl}_{6} \mathrm{NCs}$ with microcrystalline dielectric particles (here, h-BN) is to further boost the DNP enhancement by improving the homogeneity of the microwave field inside the sample. ${ }^{35,36}$

The DNP surface-enhanced ${ }^{1} \mathrm{H}-{ }^{133} \mathrm{Cs}$ spectrum of $\mathrm{Cs}_{2} \mathrm{ZrCl}_{6}$ NCs (see Figure S5 in the SI, top) shows a broad distribution of shifts, which is comparable to that recorded using conventional MAS NMR at room temperature (RT; cf. Figure 2a) and further corroborates our earlier assignment of surface $\mathrm{Cs}^{+}$environments. Despite its large line width, the DNPenhanced ${ }^{133} \mathrm{Cs}$ spectrum does resolve at least two distinct local surface Cs environments (at 104 and $124 \mathrm{ppm}$ ). While their unambiguous assignment to specific surface sites is beyond the scope of the present work, we note that similar complexity of surface signals has been previously seen in semiconducting $\mathrm{ZnSe} \mathrm{NCs}$ of various shapes and surface-tovolume ratios, ${ }^{37}$ as well as in $\mathrm{CsPbBr}_{3}$ nanocuboids ${ }^{38}$ and nanoplatelets. ${ }^{39}$ We also detect the NC core signal with an echo sequence without microwave irradiation (see Figure S5, bottom). The signal is broader than at RT $(\delta=104 \mathrm{ppm}$, FWHM $=874 \pm 18 \mathrm{~Hz}$ ), suggesting that the crystal structure undergoes slight lattice parameter changes upon going from $\mathrm{RT}$ to $100 \mathrm{~K}$. Both the core and surface signals are slightly shifted to higher frequencies at $100 \mathrm{~K}$, with respect to RT, which we also attribute to temperature-induced structural changes.

In turn, we use DNP SENS to probe the surface ligands of $\mathrm{Cs}_{2} \mathrm{ZrCl}_{6} \quad \mathrm{NCs}$. The ${ }^{1} \mathrm{H}-{ }^{13} \mathrm{C}$ spectrum (Figure $2 \mathrm{~b}$ ) yields enhancement factors of 42 and 15 for the TCE solvent and $-\mathrm{CH}_{2}-$ signals, respectively, and evidences the presence of aliphatic chains, $-\mathrm{C}=\mathrm{C}-$ moieties, as well as carbonyl $(\mathrm{C}=$ $\mathrm{O})$ groups, consistent with the presence of oleate $\left(\mathrm{OA}^{+}\right)$as a surface ligand. In particular, the $\mathrm{C}=\mathrm{O}$ signal spans $20 \mathrm{ppm}$ and has a non-Gaussian envelope, which is indicative of highly disordered $\mathrm{C}=\mathrm{O}$ groups that may originate from $\mathrm{OA}^{+}$species bound to the surface of the NCs. The ${ }^{1} \mathrm{H}-{ }^{15} \mathrm{~N}$ CP spectrum recorded under DNP SENS conditions (Figure 2c) contains a single peak $(\delta=126 \mathrm{ppm}, \mathrm{FWHM}=1343 \pm 28 \mathrm{~Hz})$, which we attribute to the $-\mathrm{NH}_{3}^{+}$group of oleylammonium $\left(\mathrm{OLA}^{+}\right)$. The large FWHM of this peak suggests the presence of highly disordered $\mathrm{OLA}^{+}$environments that may arise from surfacebound molecules. The presence of $\mathrm{OA}^{+}$and $\mathrm{OLA}^{+}$as capping agents for these systems is analogous to those seen in lead halide perovskite NCs. ${ }^{40-46}$ We note that the ${ }^{1} \mathrm{H}-{ }^{13} \mathrm{C}$ spectrum (Figure 2b) also contains $-\mathrm{C}=\mathrm{C}-$ moieties belonging to ODE used as solvent in the synthesis. This suggests that the post-synthetic workup used here yields a material that may contain traces of the unreacted precursors, which we may have not detected with XRD if they are amorphous in nature or their concentrations are below the XRD detection limit. While the large FWHM of the peak in the ${ }^{1} \mathrm{H}-{ }^{15} \mathrm{~N}$ spectrum suggests the presence of $\mathrm{OLA}^{+}$on the surface, we cannot exclude that it originates from free residual $\mathrm{OLA}^{+}$in the frozen sample. Nevertheless, we show that OLA is not necessarily required for the formation of phase-pure $\mathrm{Cs}_{2} \mathrm{ZrCl}_{6} \mathrm{NCs}$ by performing a control experiment in which we use $\mathrm{OA}$ as the sole ligand precursor. The colloidal stability of these OA-only $\mathrm{NCs}$ suggests successful $\mathrm{OA}^{+}$-capping and, as previously mentioned, this synthesis approach shows even better reproducibility than the method that also involves OLA. Figure S4 shows the TEM and HR-TEM images of $\mathrm{OA}^{+}-$ capped $\mathrm{Cs}_{2} \mathrm{ZrCl}_{6} \mathrm{NCs}$, which are very similar in size and shape to the NCs synthesized using both OLA and OA. Hence, we conclude that $\mathrm{OA}^{+}$is the predominant ligand on $\mathrm{Cs}_{2} \mathrm{ZrCl}_{6}$ $\mathrm{NCs}$, regardless of the presence/absence of OLA during synthesis. Figure $2 \mathrm{~d}$ summarizes our conclusions on the form of the NC surfaces from our combined conventional MAS and DNP SENS NMR studies.

We now assess the optical properties of the samples. Figure 3 a shows the ultraviolet-visible (UV-Vis) absorption and PL spectra of $\mathrm{Cs}_{2} \mathrm{ZrCl}_{6}$ and $\mathrm{Cs}_{2} \mathrm{ZrBr}_{6} \mathrm{NC}$ thin films deposited by drop-casting the colloidal suspensions on fused silica substrates and encapsulated by a fused silica substrate in an argon glovebox. We observe a strong absorption onset at $\sim 260 \mathrm{~nm}$ for $\mathrm{Cs}_{2} \mathrm{ZrCl}_{6}$, consistent with photoluminescence excitation 


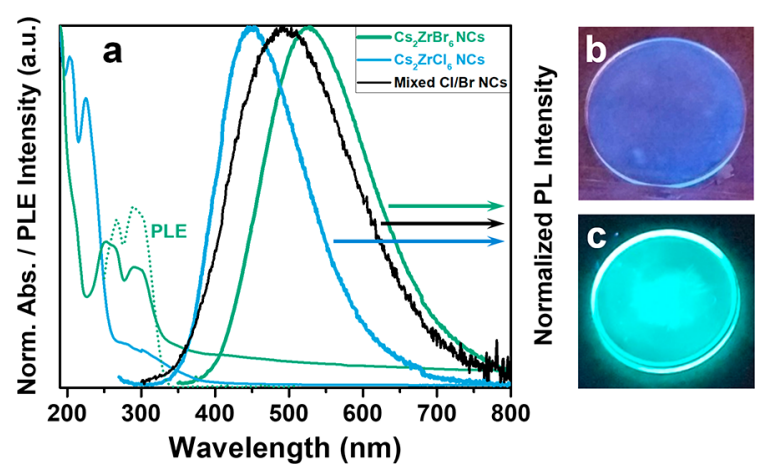

Figure 3. Optical characterization of $\mathrm{Cs}_{2} \mathrm{ZrX}_{6} \mathrm{NC}$ thin films. (a) Blue curves represent UV-Vis absorption and PL spectrum (excitation: $250 \mathrm{~nm}$ ) of encapsulated $\mathrm{Cs}_{2} \mathrm{ZrCl}_{6} \mathrm{NC}$ thin film. Green curves represent UV-Vis absorption, PLE (dotted line; emission: $519 \mathrm{~nm}$ ) and PL spectrum (excitation: $300 \mathrm{~nm}$ ) of encapsulated $\mathrm{Cs}_{2} \mathrm{ZrBr}_{6} \mathrm{NC}$ thin film. The black curve represents PL spectrum (excitation: $250 \mathrm{~nm}$ ) of encapsulated, mixed $\mathrm{Cs}_{2} \mathrm{ZrCl}_{6}$ and $\mathrm{Cs}_{2} \mathrm{ZrBr}_{6} \mathrm{NC}$ thin film. The UV-Vis absorption and PL spectra are normalized to the respective maximum intensity of the scan. The UV-Vis absorption spectrum of the $\mathrm{Cs}_{2} \mathrm{ZrBr}_{6} \mathrm{NC}$ thin film shows a broad background that we attribute to scattering. (b, c) Photographs of emission from a $\mathrm{Cs}_{2} \mathrm{ZrCl}_{6} \mathrm{NC}$ thin film (panel (b)) and a $\mathrm{Cs}_{2} \mathrm{ZrBr}_{6} \mathrm{NC}$ thin film (panel (c)) on fused silica substrates, respectively, irradiated with $254 \mathrm{~nm}$ light from a UV lamp. The PL arises from the NC thin films.

(PLE) measurements (Figure S7 in the SI), which we attribute to excitation across the band gap. The spectrum at wavelengths below this absorption onset is structured, and we tentatively assign the peaks at $\sim 203$ and $\sim 225 \mathrm{~nm}$ to the $\mathrm{Cl}\left(\mathrm{t}_{1 \mathrm{u}}(\pi+\right.$ $\sigma)) \rightarrow \mathrm{Zr}\left(\mathrm{t}_{2 \mathrm{~g}}(\mathrm{~d})\right)$ and $\mathrm{Cl}\left(\mathrm{t}_{2 \mathrm{u}}(\pi)\right) \rightarrow \mathrm{Zr}\left(\mathrm{t}_{2 \mathrm{~g}}(\mathrm{~d})\right)$ transitions, respectively, because they are in similar positions to the absorption bands reported by Brisdon et al. for $\left.\left[\left(\mathrm{C}_{2} \mathrm{H}_{5}\right)_{2} \mathrm{NH}_{2}\right)\right]_{2} \mathrm{ZrCl}_{6}$ salts. ${ }^{47}$ We provisionally attribute the weak sub-bandgap absorption with an onset at $\sim 380 \mathrm{~nm}$ to defects or impurities (e.g., ligands or unreacted precursors), although further work will be required to better understand the nature of these states. For the $\mathrm{Cs}_{2} \mathrm{ZrBr}_{6} \mathrm{NC}$ thin film, we find an absorption onset at $\sim 330 \mathrm{~nm}$ (similar for the NC suspension; see Figure S6 in the SI) and absorption peaks between this onset and $\sim 225 \mathrm{~nm}$, which may also be related to transitions similar to those observed for the $\mathrm{Cl}$ samples but now with Br.

Figure $3 \mathrm{a}$ shows the PL spectra of encapsulated $\mathrm{Cs}_{2} \mathrm{ZrCl}_{6}$ and $\mathrm{Cs}_{2} \mathrm{ZrBr}_{6} \mathrm{NC}$ thin films upon photo-excitation at 250 and $300 \mathrm{~nm}$, respectively. The spectra show broad, asymmetric peaks with maxima at $\sim 450 \mathrm{~nm}$ (blue-white) and $\sim 528 \mathrm{~nm}$ (green-white) for $\mathrm{Cs}_{2} \mathrm{ZrCl}_{6}$ and $\mathrm{Cs}_{2} \mathrm{ZrBr}_{6} \mathrm{NC}$ thin films, respectively. The PL spectra of the $\mathrm{NC}$ thin films and suspensions are similar to the spectra of the respective bulk powders (see Figure S6), and are in good agreement with reports on $\mathrm{PL}$ emission of $\mathrm{Cs}_{2} \mathrm{ZrCl}_{6}$ bulk powders ${ }^{48}$ and $\mathrm{Cs}_{2} \mathrm{ZrBr}_{6}$ crystals. ${ }^{15}$ Figures $3 \mathrm{~b}$ and $3 \mathrm{c}$ show photographs of the PL from thin films of $\mathrm{Cs}_{2} \mathrm{ZrCl}_{6} \mathrm{NCs}$ and $\mathrm{Cs}_{2} \mathrm{ZrBr}_{6} \mathrm{NCs}$, respectively, under $254 \mathrm{~nm}$ UV-light excitation, clearly showing the difference in emission color (see Figure S6 in the SI for a photograph of the NC suspension in toluene). We determine a large Stokes shift of $\sim 225 \mathrm{~nm}$ for the $\mathrm{Cs}_{2} \mathrm{ZrCl}_{6} \mathrm{NC}$ thin film sample, defined as the difference between the peak at $\sim 225 \mathrm{~nm}$ in the absorption spectrum and the peak emission at $\sim 450 \mathrm{~nm}$ in the PL spectrum, and a similar magnitude $(\sim 230 \mathrm{~nm})$ for the $\mathrm{Cs}_{2} \mathrm{ZrBr}_{6} \mathrm{NC}$ thin film sample. The progressive shift of the
absorption/PL between the $\mathrm{Cl}$ and $\mathrm{Br}$ samples demonstrates that the optical properties are also tunable in NC thin film form through halide engineering. We demonstrate this further by depositing films from precursor solutions comprised of mixed colloidal suspensions of $\mathrm{Cs}_{2} \mathrm{ZrCl}_{6}$ and $\mathrm{Cs}_{2} \mathrm{ZrBr}_{6} \mathrm{NCs}$, observing a $\mathrm{PL}$ spectrum intermediate between the two original PL peaks of pure $\mathrm{Cs}_{2} \mathrm{ZrCl}_{6}$ and $\mathrm{Cs}_{2} \mathrm{ZrBr}_{6} \mathrm{NC}$ thin films (Figure 3a); selective PLE measurements confirm the contributions to the emission from both $\mathrm{Cs}_{2} \mathrm{ZrCl}_{6}$ (higher energy emission) and $\mathrm{Cs}_{2} \mathrm{ZrBr}_{6}$ (lower energy emission) in the mixed film (see Figure S7). These observations suggest the simultaneous presence of $\mathrm{Cs}_{2} \mathrm{ZrCl}_{6}$ and $\mathrm{Cs}_{2} \mathrm{ZrBr}_{6} \mathrm{NCs}$ in the mixed sample, allowing us to tune the broad, white emission without being limited by fast anion exchange reactions that hinder such tunability in conventional lead-based $\mathrm{CsPbX}_{3}$ NCs. ${ }^{13,14}$ Although further work will be required to ascertain the exact reason for the stability of the mixed-anion $\mathrm{Cs}_{2} \mathrm{ZrX}_{6}$ NC sample in comparison to the lead-based mixed-anion perovskites, we speculate that it could be due to a lack of interstitial sites in the crystal structure of $\mathrm{Cs}_{2} \mathrm{ZrX}_{6}$, because of its structurally isolated $\mathrm{ZrX}_{6}{ }^{2-}$ octahedra.

Time-resolved PL measurements of an encapsulated $\mathrm{Cs}_{2} \mathrm{ZrBr}_{6} \mathrm{NC}$ thin film (see Figure S8 in the SI) reveal a long-lived component that we fit with a double-exponential decay yielding decay constants of $\tau_{1}=780 \pm 40 \mathrm{~ns}$ and $\tau_{2}=$ $4500 \pm 100 \mathrm{~ns}$ of comparable amplitude contribution, in good agreement with the values extracted from scintillation decay measurements on $\mathrm{Cs}_{2} \mathrm{ZrBr}_{6}$ bulk crystals. ${ }^{15}$ Furthermore, the PLQY of the $\mathrm{Cs}_{2} \mathrm{ZrBr}_{6} \mathrm{NC}$ thin film is $45 \%$ without considering emitted photons lost to thin film waveguiding (see the Characterization section in the SI), with the PLE spectrum closely matching the absorption spectrum (Figure $3 a)$. These results match well with the PLQY of the $\mathrm{Cs}_{2} \mathrm{ZrBr}_{6}$ NC suspension $(\sim 40 \%)$ and powder $(\sim 44 \%)$, demonstrating that we can effectively translate the solution or powder properties to thin film forms required for device applications. Such PLQY values are obtained even after depositing films from solutions stored under inert glovebox conditions for several months, indicating the encouraging stability of these materials. We note that instrumental limitations inhibit similar quantitative or time-resolved analyses of the $\mathrm{Cs}_{2} \mathrm{ZrCl}_{6} \mathrm{NCs}$, which requires deeper UV excitation. The combination of large Stokes shifts and broad, asymmetric PL features suggests radiative recombination may originate from self-trapped excitons, ${ }^{49}$ which has been reported for similar compounds such as $\mathrm{Cs}_{2} \mathrm{HfCl}_{6}{ }^{50-52}$ The lack of subgap contribution to the PLE spectrum of the $\mathrm{Cs}_{2} \mathrm{ZrBr}_{6} \mathrm{NC}$ thin films also indicates that radiative recombination is not due to permanent defect states. $^{53}$ The similar PLQY values of the bulk powder, NC suspensions, and NC thin films support the hypothesis that (i) the self-trapped exciton emission is intrinsic, related to the bulk, and (ii) the emission, consequently, is not strongly dependent on the crystallite size for the sizes studied here nor on its surface/volume ratio. Although further work will be required to elucidate all of the recombination processes in these $\mathrm{Cs}_{2} \mathrm{ZrX}_{6} \mathrm{NC}$ thin films, these results reveal very efficient and tunable radiative recombination.

In order to support our collective experimental findings, we perform electronic structure and optical property calculations on $\mathrm{Cs}_{2} \mathrm{ZrCl}_{6}$. We performed all periodic DFT calculations within the Vienna Ab Initio Simulation Package (VASP); ${ }^{54-57}$ further computational details are found in the SI. Relaxation of the crystal structure of $\mathrm{Cs}_{2} \mathrm{ZrCl}_{6}$ with HSE06 (the Heyd- 
Scuseria-Ernzerhof exchange-correlation functional) results in an optimized lattice parameter of $10.67 \AA$, overestimated by $\sim 3 \%$, with respect to the RT experimental lattice parameter of $10.407 \AA$ (cf. JCPDS File No. 01-074-1001). ${ }^{20}$

The band structure of $\mathrm{Cs}_{2} \mathrm{ZrCl}_{6}$ (Figure 4a), calculated using HSE06 with the addition of spin-orbit coupling (SOC),
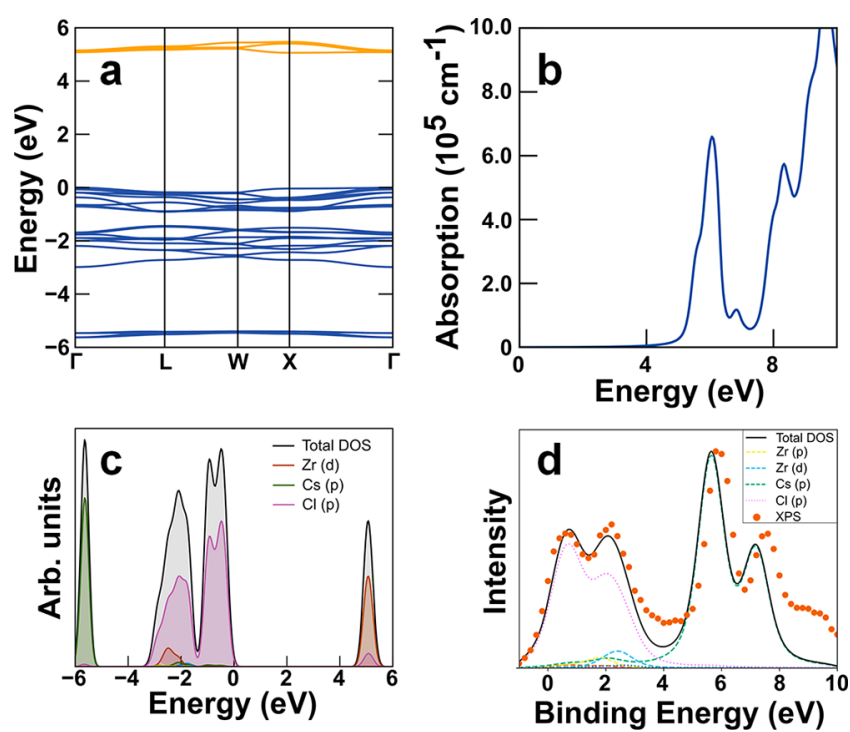

Figure 4. Electronic structure and optical property calculations within DFT-HSE on $\mathrm{Cs}_{2} \mathrm{ZrCl}_{6}$. (a) Calculated band structure for $\mathrm{Cs}_{2} \mathrm{ZrCl}_{6}$, showing the indirect $5.06 \mathrm{eV}$ fundamental band gap $(\Gamma-$ $\mathrm{X})$ and the direct band gap at $5.08 \mathrm{eV}(\Gamma-\Gamma)$. The valence and conduction bands are marked in blue and orange, respectively. The VBM is set to $0 \mathrm{eV}$. (b) Calculated absorption coefficient spectrum of $\mathrm{Cs}_{2} \mathrm{ZrCl}_{6}$. (c) Total and partial DOS of $\mathrm{Cs}_{2} \mathrm{ZrCl}_{6}$. For reasons of clarity, the legend omits labels for individual elements and corresponding orbitals that provide only minor contributions to the DOS in the regions around valence and conduction bands. (d) XPS valence band spectrum of a $\mathrm{Cs}_{2} \mathrm{ZrCl}_{6} \mathrm{NC}$ sample (orange dots), shifted by $\sim 4.5 \mathrm{eV}$ toward lower binding energies, in comparison to the photoionization cross-section weighted DOS broadened by a convolution of Gaussian and Lorentzian curves of suitable width (black curve).

demonstrates a localized nature of both valence and conduction bands, with very low dispersion in both. The structure is similar to that previously established for $\mathrm{Cs}_{2} \mathrm{HfCl}_{6}$ by hybrid DFT. ${ }^{50}$ The fundamental band gap of $\mathrm{Cs}_{2} \mathrm{ZrCl}_{6}$ at $5.06 \mathrm{eV}$ is indirect, with the valence band maximum (VBM) occurring at $\Gamma$, and the conduction band minimum (CBM) at $\mathrm{X}$. However, the minimal band dispersion means that the lowest available direct transition is only $20 \mathrm{meV}$ higher, at 5.08 $\mathrm{eV}(244 \mathrm{~nm})$, aligning well with the experimental onset of absorbance seen at $\sim 260 \mathrm{~nm}(4.77 \mathrm{eV})$ in the $\mathrm{Cs}_{2} \mathrm{ZrCl}_{6} \mathrm{NC}$ thin film sample. The HSE06+SOC band structure of $\mathrm{Cs}_{2} \mathrm{ZrBr}_{6}$ (see Figure S9 in the SI) is almost identical in shape to that of $\mathrm{Cs}_{2} \mathrm{ZrCl}_{6}$ with $\mathrm{VBM}$ and $\mathrm{CBM}$ at $\Gamma$ and $\mathrm{X}$, respectively, but with a gap of reduced magnitude, because of the substitution of $\mathrm{Cl}$ with $\mathrm{Br}$; the separation between the indirect fundamental gap $(3.91 \mathrm{eV})$ and the lowest direct transition at $\Gamma(3.93 \mathrm{eV})$ is also similar $(\sim 20 \mathrm{meV})$. This magnitude of gap is also in reasonable agreement with the experimental absorbance onset at $\sim 330 \mathrm{~nm}(3.76 \mathrm{eV})$ for the $\mathrm{Cs}_{2} \mathrm{ZrBr}_{6} \mathrm{NC}$ thin film sample. Calculation of the high-frequency dielectric function and absorption coefficient of $\mathrm{Cs}_{2} \mathrm{ZrCl}_{6}$ demonstrates that the absorption onset at the direct gap is strong, albeit localized in the 5-6 eV region, because of the narrow bandwidth of the conduction band (Figure $4 \mathrm{~b}$ ); the calculated optical absorption of $\mathrm{Cs}_{2} \mathrm{ZrBr}_{6}$ is again similar to that of $\mathrm{Cs}_{2} \mathrm{ZrCl}_{6}$, with the onset of absorption at lower energy, concomitant with the lower fundamental gap (see Figure S9).

The electronic density of states (DOS, cf. Figure 4c) calculated using HSE06+SOC, demonstrates that the valence electronic states of both $\mathrm{Cs}_{2} \mathrm{ZrCl}_{6}$ and $\mathrm{Cs}_{2} \mathrm{ZrBr}_{6}$ are highly localized: the upper valence band is fully dominated by halide $p$ states, while the conduction band primarily consists of the empty $\mathrm{Zr} d$ states mixed with some halide $p$, with the corresponding occupied states lying lower in the valence band $(-3 \mathrm{eV})$.

After weighting each orbital by its photoionization cross section and convolving with Gaussian and Lorentzian curves of suitable width to simulate experimental broadening, ${ }^{58}$ we compare the calculated electronic DOS directly with X-ray photoelectron spectroscopy (XPS) valence band spectra measured on a $\mathrm{Cs}_{2} \mathrm{ZrCl}_{6} \mathrm{NC}$ thin film sample (Figure $4 \mathrm{~d}$, orange dots). Here, for $\mathrm{Cs}_{2} \mathrm{ZrCl}_{6}$, the weighted HSE06 DOS accurately reproduces the primary features of the valence band determined from XPS measurements and, other than a shift of the Cs $p$, split by SOC, toward lower binding energies by 0.2 $\mathrm{eV}$, presents strong agreement with experiment. Such agreement between peak positions and intensities predicted by hybrid DFT with XPS is similar to previous reports in a variety of $d$-block materials in the absence of plasmon features. ${ }^{59-61} \mathrm{In}$ addition, we detect $\mathrm{Cs}, \mathrm{Zr}$, and $\mathrm{Cl}$ in the XPS survey scan (see Figure S10 and the SI for details), which is consistent with the expected presence of these elements for the $\mathrm{Cs}_{2} \mathrm{ZrCl}_{6} \mathrm{NC}$ thin film sample.

In summary, we have reported the colloidal synthesis of antifluorite $\mathrm{Cs}_{2} \mathrm{ZrCl}_{6}$ and $\mathrm{Cs}_{2} \mathrm{ZrBr}_{6} \mathrm{NC}$ samples that can be processed into thin films. We used XRD and conventional and surface-enhanced solid-state NMR measurements to confirm the structural and compositional properties of the products, validating that the surfaces are primarily capped by oleate ligands and a distribution of disordered $\mathrm{Cs}$ configurations. Thin films of the $\mathrm{Cs}_{2} \mathrm{ZrCl}_{6}$ and $\mathrm{Cs}_{2} \mathrm{ZrBr}_{6} \mathrm{NCs}$ exhibit broad blue-white and green-white $\mathrm{PL}$, respectively, with a large Stokes shift. In addition, we measured a PLQY of $45 \%$ for a $\mathrm{Cs}_{2} \mathrm{ZrBr}_{6} \mathrm{NC}$ thin film. The white emission color is tunable by modular mixing of the $\mathrm{Cs}_{2} \mathrm{ZrCl}_{6}$ and $\mathrm{Cs}_{2} \mathrm{ZrBr}_{6} \mathrm{NC}$ components, revealing that anion exchange does not limit color tunability in the same way as that observed for lead halide perovskites. We present band structure calculations, which, in turn, provide strong support for our chemical and optical experimental results. These results provide an important step toward opening up a new family of tunable lead-free emitting materials for emerging thin film optoelectronic applications, including use as light-converting phosphors and electroluminescent light-emitting diodes.

\section{ASSOCIATED CONTENT}

\section{Supporting Information}

The Supporting Information is available free of charge at https://pubs.acs.org/doi/10.1021/acsmaterialslett.0c00393.

Additional experimental details; details on sample characterization with XRD, TEM, NMR spectroscopy, UV-Vis absorption, PL, PLE and time-resolved PL spectroscopy, PLQY measurements, and XPS; computational details on DFT calculations; XRD data on sample 
degradation in air; FFT analysis on HR-TEM images of $\mathrm{Cs}_{2} \mathrm{ZrX}_{6} \mathrm{NCs}$; additional NMR, TEM, UV-Vis absorption, PL, PL decay, PLE and XPS data; results on electronic and optical property calculations on $\left.\mathrm{Cs}_{2} \mathrm{ZrBr}_{6}\right)$ (PDF)

$\mathrm{CIF}$ of $\mathrm{Cs}_{2} \mathrm{ZrBr}_{6}$ (CIF)

\section{AUTHOR INFORMATION}

\section{Corresponding Author}

Samuel D. Stranks - Cavendish Laboratory, Department of Physics and Department of Chemical Engineering and Biotechnology, University of Cambridge, Cambridge CB3 OHE, United Kingdom; (1) orcid.org/0000-0002-83037292; Email: sds65@cam.ac.uk

\section{Authors}

Anna Abfalterer - Cavendish Laboratory, Department of Physics, University of Cambridge, Cambridge CB3 OHE, United Kingdom; 10 orcid.org/0000-0002-9423-8671

Javad Shamsi - Cavendish Laboratory, Department of Physics, University of Cambridge, Cambridge CB3 OHE, United Kingdom; ○ orcid.org/0000-0003-4684-5407

Dominik J. Kubicki - Cavendish Laboratory, Department of Physics and Department of Chemistry, University of Cambridge, Cambridge CB3 OHE, United Kingdom; ○ orcid.org/0000-0002-9231-6779

Christopher N. Savory - Department of Chemistry and Thomas Young Centre, University College London, London WC1H 0AJ, United Kingdom; () orcid.org/0000-00029052-7484

James Xiao - Cavendish Laboratory, Department of Physics, University of Cambridge, Cambridge CB3 OHE, United Kingdom

Giorgio Divitini - Department of Materials Science \& Metallurgy, University of Cambridge, Cambridge CB3 OFS, United Kingdom; (1) orcid.org/0000-0003-2775-610X

Weiwei Li - Department of Materials Science \& Metallurgy, University of Cambridge, Cambridge CB3 OFS, United Kingdom; (1) orcid.org/0000-0001-5781-5401

Stuart Macpherson - Cavendish Laboratory, Department of Physics, University of Cambridge, Cambridge CB3 OHE, United Kingdom

Krzysztof Gałkowski - Cavendish Laboratory, Department of Physics, University of Cambridge, Cambridge CB3 OHE, United Kingdom; Institute of Physics, Faculty of Physics, Astronomy and Informatics, Nicolaus Copernicus University, 87-100 Torun, Poland; ㅇo이.org/0000-0002-9275-1519

Judith L. MacManus-Driscoll - Department of Materials Science \& Metallurgy, University of Cambridge, Cambridge CB3 OFS, United Kingdom

David O. Scanlon - Department of Chemistry and Thomas Young Centre, University College London, London WC1H OAJ, United Kingdom; Diamond Light Source Ltd., Diamond House, Didcot, Oxfordshire OX11 ODE, United Kingdom; (1) orcid.org/0000-0001-9174-8601

Complete contact information is available at:

https://pubs.acs.org/10.1021/acsmaterialslett.0c00393

\section{Notes}

The authors declare no competing financial interest. Additionally, the data of this publication is available under https://doi.org/10.17863/CAM.59283.

\section{ACKNOWLEDGMENTS}

S.D.S. acknowledges the Royal Society and Tata Group (UF150033). J.S. and S.D.S. acknowledge the European Research Council (ERC) under the European Union's Horizon 2020 research and innovation program (HYPERION, Grant Agreement No. 756962). This work has received funding from the European Union's Horizon 2020 Research and Innovation Program, under Marie Skłodowska-Curie Grant Agreement No. 841136. A.A. acknowledges the Royal Society for funding. We are grateful to the UK Materials and Molecular Modelling Hub for computational resources, which is partially funded by EPSRC (No. EP/P020194/1) and to UCL for the provision of the Legion (Legion@UCL), Myriad (Myriad@UCL) and Grace (Grace@UCL) computing clusters. Computational work was also performed on the ARCHER UK National Supercomputing Service, via our membership of the UK's HEC Materials Chemistry Consortium, funded by EPSRC (Nos. EP/L000202 and EP/R029431). J.X. thanks the EPSRC Cambridge NanoDTC (No. EP/L015978/1). W.-W.L. and J.L.M.-D. acknowledge support from EPSRC Grant Nos. EP/L011700/1 and EP/N004272/1, and the Isaac Newton Trust (Minute 13.38(k)). J.L.M.-D. acknowledges support from the Royal Academy of Engineering, through Grant No. CiET1819_24. This work was supported through the Cambridge Royce Facilities (Grant No. EP/P024947/1) and Sir Henry Royce Institute (recurrent Grant No. EP/R00661X/1). S.M. acknowledges an EPSRC studentship. K.G. appreciates support from the Polish Ministry of Science and Higher Education within the Mobilnosc Plus program (Grant No. 1603/MOB/V/2017/0). The DNP MAS NMR experiments were performed at the Nottingham DNP MAS NMR Facility, which is funded by the University of Nottingham and EPSRC (Nos. EP/L022524/1 and EP/R042853/1). We thank Adam Brown for support with XPS measurements.

\section{REFERENCES}

(1) Stranks, S. D. Nonradiative Losses in Metal Halide Perovskites. ACS Energy Lett. 2017, 2, 1515-1525.

(2) Giustino, F.; Snaith, H. J. Toward Lead-Free Perovskite Solar Cells. ACS Energy Lett. 2016, 1, 1233-1240.

(3) Li, J.; Cao, H.-L.; Jiao, W.-B.; Wang, Q.; Wei, M.; Cantone, I.; Lü, J.; Abate, A. Biological Impact of Lead from Halide Perovskites Reveals the Risk of Introducing a Safe Threshold. Nat. Commun. 2020, 11, 310.

(4) Xiao, Z.; Song, Z.; Yan, Y. From Lead Halide Perovskites to Lead-Free Metal Halide Perovskites and Perovskite Derivatives. Adv. Mater. 2019, 31, 1803792.

(5) Zhao, X.-G.; Yang, D.; Ren, J.-C.; Sun, Y.; Xiao, Z.; Zhang, L. Rational Design of Halide Double Perovskites for Optoelectronic Applications. Joule 2018, 2, 1662-1673.

(6) Ju, M.-G.; Chen, M.; Zhou, Y.; Garces, H. F.; Dai, J.; Ma, L.; Padture, N. P.; Zeng, X. C. Earth-Abundant Nontoxic Titanium(IV)Based Vacancy-Ordered Double Perovskite Halides with Tunable 1.0 to $1.8 \mathrm{eV}$ Bandgaps for Photovoltaic Applications. ACS Energy Lett. 2018, 3, 297-304.

(7) Evans, H. A.; Fabini, D. H.; Andrews, J. L.; Koerner, M.; Preefer, M. B.; Wu, G.; Wudl, F.; Cheetham, A. K.; Seshadri, R. Hydrogen Bonding Controls the Structural Evolution in Perovskite-Related Hybrid Platinum(IV) Iodides. Inorg. Chem. 2018, 57, 10375-10382.

(8) Sakai, N.; Haghighirad, A. A.; Filip, M. R.; Nayak, P. K.; Nayak, S.; Ramadan, A.; Wang, Z.; Giustino, F.; Snaith, H. J. SolutionProcessed Cesium Hexabromopalladate(IV), $\mathrm{Cs}_{2} \mathrm{PdBr}_{6}$, for Optoelectronic Applications. J. Am. Chem. Soc. 2017, 139, 6030-6033.

(9) Chen, M.; Ju, M.-G.; Carl, A. D.; Zong, Y.; Grimm, R. L.; Gu, J.; Zeng, X. C.; Zhou, Y.; Padture, N. P. Cesium Titanium(IV) Bromide 
Thin Films Based Stable Lead-Free Perovskite Solar Cells. Joule 2018, 2, 558-570.

(10) Saparov, B.; Sun, J.-P.; Meng, W.; Xiao, Z.; Duan, H.-S.; Gunawan, O.; Shin, D.; Hill, I. G.; Yan, Y.; Mitzi, D. B. Thin-Film Deposition and Characterization of a Sn-Deficient Perovskite Derivative $\mathrm{Cs}_{2} \mathrm{SnI}_{6}$. Chem. Mater. 2016, 28, 2315-2322.

(11) Zhou, L.; Liao, J.-F.; Huang, Z.-G.; Wang, X.-D.; Xu, Y.-F.; Chen, H.-Y.; Kuang, D.-B.; Su, C.-Y. All-Inorganic Lead-Free Cs2PdX6 (X = Br, I) Perovskite Nanocrystals with Single Unit Cell Thickness and High Stability. ACS Energy Lett. 2018, 3, 2613-2619.

(12) Wang, A.; Yan, X.; Zhang, M.; Sun, S.; Yang, M.; Shen, W.; Pan, X.; Wang, P.; Deng, Z. Controlled Synthesis of Lead-Free and Stable Perovskite Derivative $\mathrm{Cs}_{2} \mathrm{SnI}_{6}$ Nanocrystals via a Facile Hot-Injection Process. Chem. Mater. 2016, 28, 8132-8140.

(13) Nedelcu, G.; Protesescu, L.; Yakunin, S.; Bodnarchuk, M. I.; Grotevent, M. J.; Kovalenko, M. V. Fast Anion-Exchange in Highly Luminescent Nanocrystals of Cesium Lead Halide Perovskites $(\mathrm{CsPbX}, \mathrm{X}=\mathrm{Cl}, \mathrm{Br}, \mathrm{I})$. Nano Lett. 2015, 15, 5635-5640.

(14) Akkerman, Q. A.; D’Innocenzo, V.; Accornero, S.; Scarpellini, A.; Petrozza, A.; Prato, M.; Manna, L. Tuning the Optical Properties of Cesium Lead Halide Perovskite Nanocrystals by Anion Exchange Reactions. J. Am. Chem. Soc. 2015, 137, 10276-10281.

(15) Saeki, K.; Fujimoto, Y.; Koshimizu, M.; Nakauchi, D.; Tanaka, H.; Yanagida, T.; Asai, K. Luminescence and Scintillation Properties of $\mathrm{Cs}_{2} \mathrm{HfBr}_{6}$ and $\mathrm{Cs}_{2} \mathrm{ZrBr}_{6}$ Crystals. Jpn. J. Appl. Phys. 2018, 57, 030310 .

(16) Saeki, K.; Fujimoto, Y.; Koshimizu, M.; Yanagida, T.; Asai, K. Comparative Study of Scintillation Properties of $\mathrm{Cs}_{2} \mathrm{HfCl}_{6}$ and $\mathrm{Cs}_{2} \mathrm{ZrCl}_{6}$. Appl. Phys. Express 2016, 9, 042602.

(17) Protesescu, L.; Yakunin, S.; Bodnarchuk, M. I.; Krieg, F.; Caputo, R.; Hendon, C. H.; Yang, R. X.; Walsh, A.; Kovalenko, M. V. Nanocrystals of Cesium Lead Halide Perovskites (CsPbX3, X $=\mathrm{Cl}$, $\mathrm{Br}$, and I): Novel Optoelectronic Materials Showing Bright Emission with Wide Color Gamut. Nano Lett. 2015, 15, 3692-3696.

(18) Imran, M.; Caligiuri, V.; Wang, M.; Goldoni, L.; Prato, M.; Krahne, R.; De Trizio, L.; Manna, L. Benzoyl Halides as Alternative Precursors for the Colloidal Synthesis of Lead-Based Halide Perovskite Nanocrystals. J. Am. Chem. Soc. 2018, 140, 2656-2664.

(19) Drummen, P. J. H.; Donker, H.; Smit, W. M. A.; Blasse, G. Jahn-Teller Distortion in the Excited State of Tellurium(IV) in $\mathrm{Cs}_{2} \mathrm{MCl}_{6}(\mathrm{M}=\mathrm{Zr}, \mathrm{Sn})$. Chem. Phys. Lett. 1988, 144, 460-462.

(20) Engel, G. Die Kristallstrukturen Einiger Hexachlorokomplexsalze. Z. Kristallogr. - Cryst. Mater. 1935, 90, 341-373.

(21) Momma, K.; Izumi, F. VESTA 3 for Three-Dimensional Visualization of Crystal, Volumetric and Morphology Data. J. Appl. Crystallogr. 2011, 44, 1272-1276.

(22) Swanson, H. E.; Fuyat, R. K.; Ugrinic, G. M. Standard X-Ray Diffraction Powder Patterns. Natl. Bur. Stand. (U.S.) 1954, 3, 49 (Circular 539).

(23) Metcalf, D. H.; Dai, S.; Del Cul, G. D.; Toth, L. M. Luminescence Spectra of Single Crystals of $\mathrm{Cs}_{2} \mathrm{ZrCl}_{6}: \mathrm{UO}_{2} \mathrm{Cl}_{4}{ }^{2-}$ at Low Temperatures. Vibronic Structure of $\mathrm{UO}_{2}{ }^{2+}$ Doped in a Cubic Host. Inorg. Chem. 1995, 34, 5573-5577.

(24) Xu, W.; Dai, S.; Toth, L. M.; Peterson, J. R. Blue UpConversion Emission from $\mathrm{U}^{4+}$-Ion Doped into $\mathrm{Cs}_{2} \mathrm{ZrCl}_{6}$ Single Crystal under Green Light $\left(19436 \mathrm{~cm}^{-1}\right)$ Excitation. Chem. Phys. 1995, 193, 339-344.

(25) Aebischer, A.; Salley, G. M.; Güdel, H. U. Near Infrared to Visible Photon Upconversion in $\mathrm{Re}^{4+}$ Doped $\mathrm{Cs}_{2} \mathrm{ZrBr}_{6}$. J. Chem. Phys. 2002, 117, 8515-8522.

(26) Rossini, A. J.; Zagdoun, A.; Lelli, M.; Gajan, D.; Rascón, F.; Rosay, M.; Maas, W. E.; Copéret, C.; Lesage, A.; Emsley, L. One Hundred Fold Overall Sensitivity Enhancements for Silicon-29 NMR Spectroscopy of Surfaces by Dynamic Nuclear Polarization with CPMG Acquisition. Chem. Sci. 2012, 3, 108-115.

(27) Rossini, A. J.; Zagdoun, A.; Lelli, M.; Lesage, A.; Copéret, C.; Emsley, L. Dynamic Nuclear Polarization Surface Enhanced NMR Spectroscopy. Acc. Chem. Res. 2013, 46, 1942-1951.
(28) Protesescu, L.; Rossini, A. J.; Kriegner, D.; Valla, M.; de Kergommeaux, A.; Walter, M.; Kravchyk, K. V.; Nachtegaal, M.; Stangl, J.; Malaman, B.; Reiss, P.; Lesage, A.; Emsley, L.; Copéret, C.; Kovalenko, M. V. Unraveling the Core-Shell Structure of LigandCapped $\mathrm{Sn} / \mathrm{SnO}_{\mathrm{x}}$ Nanoparticles by Surface-Enhanced Nuclear Magnetic Resonance, Mössbauer, and X-Ray Absorption Spectroscopies. ACS Nano 2014, 8, 2639-2648.

(29) Piveteau, L.; Ong, T.-C.; Rossini, A. J.; Emsley, L.; Copéret, C.; Kovalenko, M. V. Structure of Colloidal Quantum Dots from Dynamic Nuclear Polarization Surface Enhanced NMR Spectroscopy. J. Am. Chem. Soc. 2015, 137, 13964-13971.

(30) Walder, B. J.; Berk, C.; Liao, W.-C.; Rossini, A. J.; Schwarzwälder, M.; Pradere, U.; Hall, J.; Lesage, A.; Copéret, C.; Emsley, L. One- and Two-Dimensional High-Resolution NMR from Flat Surfaces. ACS Cent. Sci. 2019, 5, 515-523.

(31) Zagdoun, A.; Casano, G.; Ouari, O.; Lapadula, G.; Rossini, A. J.; Lelli, M.; Baffert, M.; Gajan, D.; Veyre, L.; Maas, W. E.; Rosay, M.; Weber, R. T.; Thieuleux, C.; Coperet, C.; Lesage, A.; Tordo, P.; Emsley, L. A Slowly Relaxing Rigid Biradical for Efficient Dynamic Nuclear Polarization Surface-Enhanced NMR Spectroscopy: Expeditious Characterization of Functional Group Manipulation in Hybrid Materials. J. Am. Chem. Soc. 2012, 134, 2284-2291.

(32) Maly, T.; Miller, A.-F.; Griffin, R. G. In Situ High-Field Dynamic Nuclear Polarization-Direct and Indirect Polarization of ${ }^{13} \mathrm{C}$ Nuclei. ChemPhysChem 2010, 11, 999-1001.

(33) Abragam, A. The Principles of Nuclear Magnetism; International Series of Monographs on Physics; Oxford University Press: Oxford, U.K., 1961.

(34) Pines, A.; Gibby, M. G.; Waugh, J. S. Proton-Enhanced Nuclear Induction Spectroscopy ${ }^{13} \mathrm{C}$ Chemical Shielding Anisotropy in Some Organic Solids. Chem. Phys. Lett. 1972, 15, 373-376.

(35) Kubicki, D. J.; Rossini, A. J.; Purea, A.; Zagdoun, A.; Ouari, O.; Tordo, P.; Engelke, F.; Lesage, A.; Emsley, L. Amplifying Dynamic Nuclear Polarization of Frozen Solutions by Incorporating Dielectric Particles. J. Am. Chem. Soc. 2014, 136, 15711-15718.

(36) Hanrahan, M. P.; Chen, Y.; Blome-Fernández, R.; Stein, J. L.; Pach, G. F.; Adamson, M. A. S.; Neale, N. R.; Cossairt, B. M.; Vela, J.; Rossini, A. J. Probing the Surface Structure of Semiconductor Nanoparticles by DNP SENS with Dielectric Support Materials. J. Am. Chem. Soc. 2019, 141, 15532-15546.

(37) Cadars, S.; Smith, B. J.; Epping, J. D.; Acharya, S.; Belman, N.; Golan, Y.; Chmelka, B. F. Atomic Positional Versus Electronic Order in Semiconducting ZnSe Nanoparticles. Phys. Rev. Lett. 2009, 103, 136802 .

(38) Chen, Y.; Smock, S. R.; Flintgruber, A. H.; Perras, F. A.; Brutchey, R. L.; Rossini, A. J. Surface Termination of $\mathrm{CsPbBr}$ Perovskite Quantum Dots Determined by Solid-State NMR Spectroscopy. J. Am. Chem. Soc. 2020, 142, 6117-6127.

(39) Shamsi, J.; Kubicki, D.; Anaya, M.; Liu, Y.; Ji, K.; Frohna, K.; Grey, C. P.; Friend, R. H.; Stranks, S. D. Stable HexylphosphonateCapped Blue-Emitting Quantum-Confined $\mathrm{CsPbBr}_{3}$ Nanoplatelets. ACS Energy Lett. 2020, 5, 1900-1907.

(40) Imran, M.; Ijaz, P.; Baranov, D.; Goldoni, L.; Petralanda, U.; Akkerman, Q.; Abdelhady, A. L.; Prato, M.; Bianchini, P.; Infante, I.; Manna, L. Shape-Pure, Nearly Monodispersed $\mathrm{Cs}_{\mathrm{PbBr}}$ Nanocubes Prepared Using Secondary Aliphatic Amines. Nano Lett. 2018, 18, $7822-7831$.

(41) Yassitepe, E.; Yang, Z.; Voznyy, O.; Kim, Y.; Walters, G.; Castañeda, J. A.; Kanjanaboos, P.; Yuan, M.; Gong, X.; Fan, F.; Pan, J.; Hoogland, S.; Comin, R.; Bakr, O. M.; Padilha, L. A.; Nogueira, A. F.; Sargent, E. H. Amine-Free Synthesis of Cesium Lead Halide Perovskite Quantum Dots for Efficient Light-Emitting Diodes. Adv. Funct. Mater. 2016, 26, 8757-8763.

(42) Krieg, F.; Ochsenbein, S. T.; Yakunin, S.; Ten Brinck, S.; Aellen, P.; Süess, A.; Clerc, B.; Guggisberg, D.; Nazarenko, O.; Shynkarenko, Y.; Kumar, S.; Shih, C.-J.; Infante, I.; Kovalenko, M. V. Colloidal $\mathrm{CsPbX}_{3}(\mathrm{X}=\mathrm{Cl}, \mathrm{Br}, \mathrm{I})$ Nanocrystals 2.0: Zwitterionic Capping Ligands for Improved Durability and Stability. ACS Energy Lett. 2018, 3, 641-646. 
(43) De Roo, J.; Ibáñez, M.; Geiregat, P.; Nedelcu, G.; Walravens, W.; Maes, J.; Martins, J. C.; Van Driessche, I.; Kovalenko, M. V.; Hens, Z. Highly Dynamic Ligand Binding and Light Absorption Coefficient of Cesium Lead Bromide Perovskite Nanocrystals. ACS Nano 2016, 10, 2071-2081.

(44) Ravi, V. K.; Santra, P. K.; Joshi, N.; Chugh, J.; Singh, S. K.; Rensmo, H.; Ghosh, P.; Nag, A. Origin of the Substitution Mechanism for the Binding of Organic Ligands on the Surface of $\mathrm{CsPbBr}_{3}$ Perovskite Nanocubes. J. Phys. Chem. Lett. 2017, 8, 49884994.

(45) Bodnarchuk, M. I.; Boehme, S. C.; Ten Brinck, S.; Bernasconi, C.; Shynkarenko, Y.; Krieg, F.; Widmer, R.; Aeschlimann, B.; Günther, D.; Kovalenko, M. V.; Infante, I. Rationalizing and Controlling the Surface Structure and Electronic Passivation of Cesium Lead Halide Nanocrystals. ACS Energy Lett. 2019, 4, 63-74.

(46) Imran, M.; Ijaz, P.; Goldoni, L.; Maggioni, D.; Petralanda, U.; Prato, M.; Almeida, G.; Infante, I.; Manna, L. Simultaneous Cationic and Anionic Ligand Exchange For Colloidally Stable $\mathrm{CsPBr}_{3}$ Nanocrystals. ACS Energy Lett. 2019, 4, 819-824.

(47) Brisdon, B. J.; Lester, T. E.; Walton, R. A. Complex Halides of Transition Metals-III Electronic Absorption Spectra of Hexahalotitanates(IV), Vanadates(IV), and Zirconates(IV). Spectrochim. Acta, Part A 1967, 23, 1969-1976.

(48) Bryan, P. S.; Ferranti, S. A. Luminescence of $\mathrm{Cs}_{2} \mathrm{ZrCl}_{6}$ and $\mathrm{Cs}_{2} \mathrm{HfCl}_{6}$. J. Lumin. 1984, 31-32, 117-119.

(49) Li, S.; Luo, J.; Liu, J.; Tang, J. Self-Trapped Excitons in AllInorganic Halide Perovskites: Fundamentals, Status, and Potential Applications. J. Phys. Chem. Lett. 2019, 10, 1999-2007.

(50) Kang, By; Biswas, K. Carrier Self-Trapping and Luminescence in Intrinsically Activated Scintillator: Cesium Hafnium Chloride $\left(\mathrm{Cs}_{2} \mathrm{HfCl}_{6}\right)$. J. Phys. Chem. C 2016, 120, 12187-12195.

(51) Buryi, M.; Král, R.; Babin, V.; Páterek, J.; Vaněček, V.; Veverka, P.; Kohoutková, M.; Laguta, V.; Fasoli, M.; Villa, I.; Cova, F.; Vedda, A.; Nikl, M. Trapping and Recombination Centers in Cesium Hafnium Chloride Single Crystals: EPR and TSL Study. J. Phys. Chem. C 2019, 123, 19402-19411.

(52) Král, R.; Babin, V.; Mihóková, E.; Buryi, M.; Laguta, V. V.; Nitsch, K.; Nikl, M. Luminescence and Charge Trapping in $\mathrm{Cs}_{2} \mathrm{HfCl}_{6}$ Single Crystals: Optical and Magnetic Resonance Spectroscopy Study. J. Phys. Chem. C 2017, 121, 12375-12382.

(53) Smith, M. D.; Karunadasa, H. I. White-Light Emission from Layered Halide Perovskites. Acc. Chem. Res. 2018, 51, 619-627.

(54) Kresse, G.; Hafner, J. Ab Initio Molecular Dynamics for Liquid Metals. Phys. Rev. B: Condens. Matter Mater. Phys. 1993, 47, 558-561.

(55) Kresse, G.; Hafner, J. Ab Initio Molecular-Dynamics Simulation of the Liquid-Metal-Amorphous-Semiconductor Transition in Germanium. Phys. Rev. B: Condens. Matter Mater. Phys. 1994, 49, 14251-14269.

(56) Kresse, G.; Furthmüller, J. Efficiency of Ab-Initio Total Energy Calculations for Metals and Semiconductors Using a Plane-Wave Basis Set. Comput. Mater. Sci. 1996, 6, 15-50.

(57) Kresse, G.; Furthmüller, J. Efficient Iterative Schemes for Ab Initio Total-Energy Calculations Using a Plane-Wave Basis Set. Phys. Rev. B: Condens. Matter Mater. Phys. 1996, 54, 11169-11186.

(58) Jackson, A. J.; Ganose, A. M.; Regoutz, A.; Egdell, R. G.; Scanlon, D. O. Galore: Broadening and Weighting for Simulation of Photoelectron Spectroscopy. JOSS 2018, 3, 773.

(59) Savory, C. N.; Ganose, A. M.; Travis, W.; Atri, R. S.; Palgrave, R. G.; Scanlon, D. O. An Assessment of Silver Copper Sulfides for Photovoltaic Applications: Theoretical and Experimental Insights. J. Mater. Chem. A 2016, 4, 12648-12657.

(60) Sathasivam, S.; Williamson, B. A. D.; Althabaiti, S. A.; Obaid, A. Y.; Basahel, S. N.; Mokhtar, M.; Scanlon, D. O.; Carmalt, C. J.; Parkin, I. P. Chemical Vapor Deposition Synthesis and Optical Properties of $\mathrm{Nb}_{2} \mathrm{O}_{5}$ Thin Films with Hybrid Functional Theoretical Insight into the Band Structure and Band Gaps. ACS Appl. Mater. Interfaces 2017, 9, 18031-18038.

(61) Regoutz, A.; Ganose, A. M.; Blumenthal, L.; Schlueter, C.; Lee, T.-L.; Kieslich, G.; Cheetham, A. K.; Kerherve, G.; Huang, Y.-S.;
Chen, R.-S.; Vinai, G.; Pincelli, T.; Panaccione, G.; Zhang, K. H. L.; Egdell, R. G.; Lischner, J.; Scanlon, D. O.; Payne, D. J. Insights into the Electronic Structure of $\mathrm{OsO}_{2}$ Using Soft and Hard X-Ray Photoelectron Spectroscopy in Combination with Density Functional Theory. Phys. Rev. Materials 2019, 3, 025001. 